\title{
Study of Upper Gastrointestinal Tract Endoscopic Findings in Portal Hypertension
}

\author{
Lochan Karki, ${ }^{1}$ Manen Prasad Gorkhaly, ${ }^{1}$ Buddha Bahadur Karki ${ }^{1}$ \\ 'National Academy of Medical Sciences, Bir Hospital, Kathmandu, Nepal.
}

\section{ABSTRACT}

Introduction: The gut mucosa in portal hypertension is the seat of microcirculatory changes that compromise its integrity and increase its susceptibility to damage. The mucosal changes in portal hypertension may require pharmacological, directed endoscopic or portal decompressive therapy. The objective of the study is to find out various upper gastrointestinal tract endoscopic findings in patients of portal hypertension.

Methods: A prospective, cross-sectional, observational study of sixty patients of portal hypertension was conducted from June to October 2009. The esophagus, stomach and upper duodenum was visualized for any changes, especially by taking the tip of the instrument close to the mucosa.

Results: Out of total, 60, $47(78.3 \%)$ cases were cirrhotic and 13 (21.7\%) cases were non-cirrhotic portal hypertension. The most frequent upper GI endoscopic finding was esophageal varices 56 $(98.3 \%)$ followed by gastropathy $49(81.6 \%)$, gastric hyperemia $19(31.6 \%)$, duodenal hyperemia and erosive gastritis 16 (26.6\% in each) and gastric varices 12 (20\%). Esophageal varices were equally prevalent among cirrhotic and non cirrhotic portal hypertensive patients, 46 out of $47(97.9 \%)$ and 13 out of 13 (100\%) respectively. Gastropathy was more prevalent in cirrhotic patients with $87.2 \%$ vs. $75 \%$ in NCPF followed by $40 \%$ in EHO. However, duodenal ulcers were seen only in EHO $12.5 \%$. Erosive gastritis was more prevalent in EHO (75\%) followed by NCPF (60\%), however, it was less frequent in cirrhotic portal hypertension $(14.8 \%)$.

Conclusions: The most common upper GI endoscopic finding in portal hypertensive patients were found to be esophageal varices followed by gastropathy, peptic ulcer disease (gastric and duodenal hyperemia, chronic gastritis, erosive gastritis, gastric ulcer and duodenal ulcer).

Keywords: gastrointestinal tract; portal hypertension; varices.

\section{INTRODUCTION}

Portal Hypertension is defined as a clinical syndrome manifested by hemodynamic changes due to difficult blood outflow from the portal bed. ${ }^{1}$ The common causes of portal hypertension are cirrhosis of liver, non -cirrhotic portal fibrosis and extra hepatic portal vein obstruction due to umbilical sepsis. It may be due to hepatic outflow obstruction of varied etiology. ${ }^{2}$ Although majority of these bleed is due to ruptured gastro esophageal varices some of these bleed may be from ectopic varies at other sites of gastrointestinal tract or

Correspondence: Dr. Lochan Karki, National Academy of Medical Sciences, Bir Hospital, Kathmandu, Nepal. Email: drlochankarki@ gmail.com, Phone: 9851056689. 
from different non variceal lesion like portohypertensive gastroduodenopathy, gastroduodenal ulcer, Mallory Weiss tear, esophago-gastroduodenitis etc. These complementary processes of vasoreactivity and vascular remodeling contribute importantly to increased intra hepatic resistance and represent important targets in the treatment of portal hypertension. ${ }^{3}$

The topic of varices (esophageal, gastric or ectopic) is well studied, however, the mucosal changes in the context of $\mathrm{PH}$ needs further elaboration. ${ }^{4}$ Therefore need is felt to undertake present study for generating data on various aspects of problems encountered in day to day practice in a referral centre to establish early diagnosis of the etiology, exact site and nature of the bleed and rational management to improve the overall outcome of the disease.

\section{METHODS}

A Prospective, cross-sectional observational study of sixty patients of portal hypertension was conducted from Jun, 2008 - Oct, 2009 (15 months) in the Gastroenterology Unit of Department of Medicine, Bir hospital.

Patients with portal hypertension (diagnosed on the basis of history and clinical examination, biochemical analysis, serum ascitic albumin gradient $>1.1$, ultrasonogram showing splenic index $>20 \mathrm{~cm},{ }^{2}$ portal vein trunk $>15$ $\mathrm{mm}$, splenic vein $>10 \mathrm{~mm}$, portal systemic collaterals, extra hepatic or portal vein obstruction, cavernous transformation, ascitis) with or without history of upper gastrointestinal bleeding and hepatic encephalopathy and fit for upper Gl endoscopy attending outpatient medical services as well as hospitalized in medical, gastroenterology and hepatobiliary ward were included in the study. Patient with portal hypertension but unfit for upper GI endoscopy e.g. shock, uncooperative, unconscious, recent $\mathrm{Ml}$, arrhythmia, restless etc and age less than 15 years were excluded from the study.

Ethical approval was taken from the concerned authority. Informed written and verbal consent was also taken from the patient. Patients were subjected to endoscopy using video endoscope (Fujinon video endoscope) without any premedication. In all patients, gastroenterologist and trained endoscopist at Bir hospital carried out an upper gastrointestinal endoscopy and required laboratory investigations.

Endoscopy was performed in left lateral position by a forward viewing video endoscope (Fujinon video endoscope). During the examination, esophagus was carefully looked for esophageal varices, any ulcers, esophagitis or any other abnormalities.

\begin{tabular}{|c|c|c|c|c|}
\hline I & $\begin{array}{l}\text { On the } \\
\text { inspiration only }\end{array}$ & $\begin{array}{l}\text { Could be } \\
\text { effaced }\end{array}$ & Straight & Red \\
\hline II & $\begin{array}{l}\text { Both the } \\
\text { inspiration and } \\
\text { expiration only }\end{array}$ & $\begin{array}{l}\text { Could be } \\
\text { effaced }\end{array}$ & $\begin{array}{l}\text { Straight } \\
\pm \text { wavy }\end{array}$ & Red \\
\hline III & $\begin{array}{l}\text { Projecting in } \\
\text { lumen }<50 \%\end{array}$ & $\begin{array}{l}\text { Couldn't be } \\
\text { effaced }\end{array}$ & $\begin{array}{l}\text { Straight } \\
\text { Wavy } \\
\text { and } \\
\pm \frac{}{\text { tortuous }}\end{array}$ & $\begin{array}{l}\text { Red/ } \\
\text { Blue }\end{array}$ \\
\hline IV & $\begin{array}{l}\text { Projecting in } \\
\text { lumen }>50 \%\end{array}$ & $\begin{array}{l}\text { Couldn't be } \\
\text { effaced and } \\
\text { tense }\end{array}$ & $\begin{array}{l}\text { Straight } \\
\text { Wavy } \\
\text { and } \\
\text { tortuous }\end{array}$ & Blue \\
\hline
\end{tabular}

The stomach and upper duodenum was visualized for the changes, especially by taking the tip of the instrument close to the mucosa. The fundus for the stomach was carefully looked to detect the portohypertensive gastropathy, fundal varices and gastric varices. Congestive gastropathic change was noted in the antrum, body fundus or whole stomach.

Data were analyzed by using SPSS 17 and Microsoft Excel.

\section{RESULTS}

Out of total 60 cases, there were $47(78.3 \%)$ cases of cirrhotic and $13(21.7 \%)$ non-cirrhotic portal hypertension. Among non cirrhotic portal hypertension $8(61.6 \%)$ were non cirrhotic portal fibrosis (NCPF) and $5(38.4 \%)$ were extra hepatic portal obstruction (EPO).

Among portal hypertensive patients the most frequent upper $\mathrm{Gl}$ endoscopic change is esophageal varices 59 $(98.3 \%)$ followed by gastropathy $49(81.6 \%)$, Gastric hyperemia 19 (31.6\%), duodenal hyperemia $16(26.6 \%)$ and erosive gastritis 16 (26.64) (Table 2).

\begin{tabular}{|ll|}
\hline \multicolumn{2}{|l|}{ Table 2. Upper gastrointestinal endoscopic } \\
observation in portal hypertension. \\
\hline Endoscopic Findings & $\mathbf{n}(\%)$ \\
Esophageal Varices & $59(98.3 \%)$ \\
Gastropathy & $49(81.6 \%)$ \\
Gastric Hyperemia & $19(31.6 \%)$ \\
Duodenal Hyperemia & $16(26.6 \%)$ \\
Erosive Gastritis & $16(26.6 \%)$ \\
Gastric Varices & $12(20 \%)$ \\
Chronic Gastritis & $8(13.3 \%)$ \\
Gastric Ulcer & $4(6.7 \%)$ \\
Gastoduodenitis & $3(5 \%)$ \\
Duodenal ulcer & $1(1.7 \%)$ \\
Total & $60(100 \%)$ \\
\hline
\end{tabular}


Esophageal varices are equally prevalent among cirrhotic and non-cirrhotic portal hypertensive patients, 46 out of $47(97.9 \%)$ and 13 out of $13(100 \%)$ respectively. Among non-cirrhotic patients, esophageal varices are present equally in EPO and NCPF (100\% in each). Gastropathy is more prevalent in cirrhotic patients with $87.2 \%$ (41 out of 47 ) vs. $75 \%$ (six out of eight) in NCPF followed by $40 \%$ (two out of five) in EPO. Gastric varices, chronic gastritis, gastroduodenitis and gastric ulcers were found only in cirrhotic portal hypertensive patients. However, duodenal ulcers were seen only in EPO $12.5 \%$ (one out of eight). Erosive gastritis was more prevalent in EPO, six out of eight $(75 \%)$ followed by three out of five $(60 \%)$ in NCPF, however, it was less frequent in cirrhotic portal hypertension seven out of $47(14.8 \%)$ (Table 3$)$.

Table 3. Upper gastrointestinal endoscopic observation in portal hypertension.

\begin{tabular}{|llll|}
\hline GI Findings & Cirrhosis & \multicolumn{2}{l|}{ Non Cirrhosis (n=13) } \\
(n=47) & EPO (5) & NCPF (8) \\
$\begin{array}{l}\text { Esophageal } \\
\text { Varices }\end{array}$ & $46(97.9 \%)$ & $5(100.00 \%)$ & $8(100.00 \%)$ \\
$\begin{array}{l}\text { Gastropathy } \\
\text { Hyperemia } \\
\text { Duodenal } \\
\text { Hyperemia }\end{array}$ & $41(87.2 \%)$ & $2(40.00 \%)$ & $6(75.000 \%)$ \\
$\begin{array}{l}\text { Esophageal } \\
\text { Varices }\end{array}$ & $15(19.9 \%)$ & $1(20.00 \%)$ & $3(37.5 \%)$ \\
$\begin{array}{l}\text { Gastric Varices } \\
\text { Chronic }\end{array}$ & $8(17 \%)$ & $2(40.00 \%)$ & $5(62.5 \%)$ \\
$\begin{array}{l}\text { Gastritis } \\
\begin{array}{l}\text { Erosive } \\
\text { Gastritis }\end{array}\end{array}$ & $7(14.8 \%)$ & $3(60.00 \%)$ & $6(75 \%)$ \\
$\begin{array}{l}\text { Gastroduod- } \\
\text { enitis }\end{array}$ & $4(8.5 \%)$ & $0(0 \%)$ & $0(0 \%)$ \\
$\begin{array}{l}\text { Gastric Ulcer } \\
\text { Duodenal } \\
\text { Ulcer }\end{array}$ & $0(0 \%)$ & $0(0 \%)$ & $1(12.5 \%)$ \\
\hline
\end{tabular}

Grade II varices are the most common findings accounting $43.5 \%$ followed by grade IV $(28.26 \%)$ and Grade III (21.74\%) among cirrhotic portal hypertensive patients. In NCPF and EPO, grade II varices are frequent accounting $37.5 \%$ and $60 \%$ respectively followed by III and IV both accounting equal in frequency, $25 \%$ in NCPF and $20 \%$ in EPO (Table 4).

\begin{tabular}{|llll|}
\hline \multicolumn{4}{|l|}{ Table 4. Esophageal varices grading in portal } \\
hypertension. \\
\hline Gl findings & Cirrhosis(47) & EPO(5) & NCPF(8) \\
I & $3(6.5 \%)$ & $0(0 \%)$ & $1(12.5 \%)$ \\
II & $20(43.5 \%)$ & $3(60 \%)$ & $3(37.5 \%)$ \\
III & $10(21.74 \%)$ & $1(20 \%)$ & $2(25.0 \%)$ \\
IV & $13(28.26 \%)$ & $1(20 \%)$ & $2(25.0 \%)$ \\
Total & $46(97.9 \%)$ & $5(100 \%)$ & $8(100 \%)$ \\
\hline
\end{tabular}

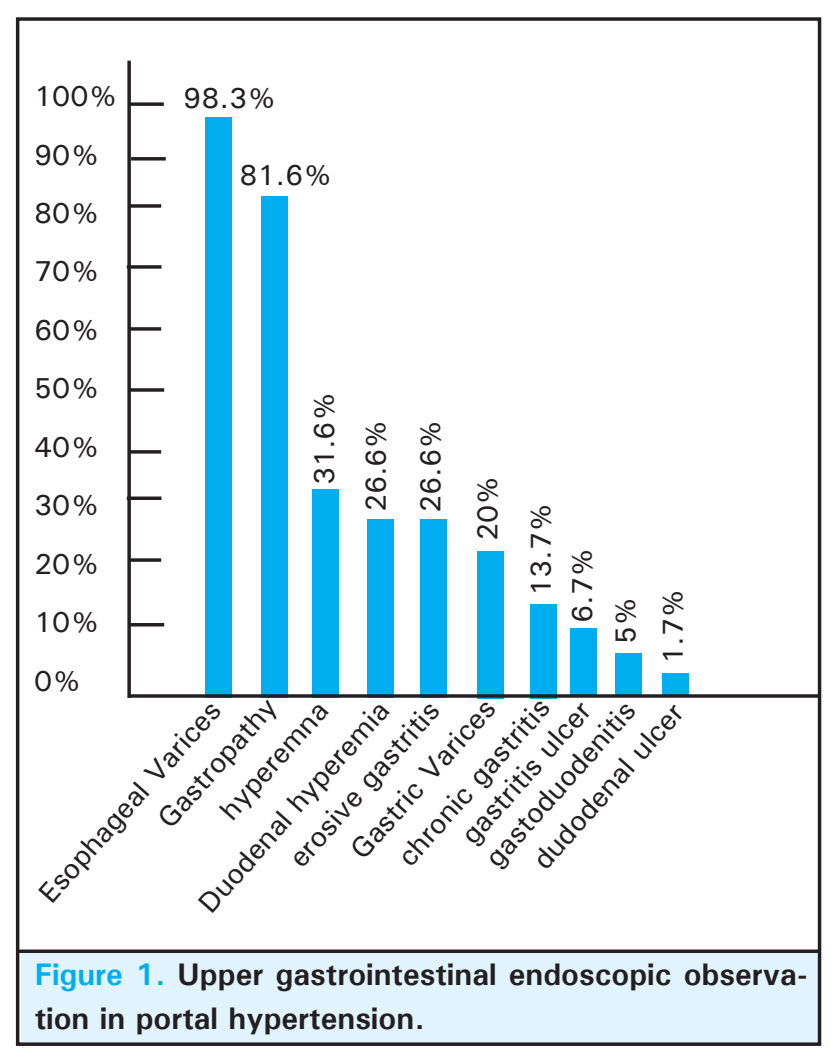

The prevalence of portal hypertension was found high in age group between 30 to 49 years, accounting $38.3 \%$ among 40 to 49 years age group and $30 \%$ among 30 to 39 years age group (Figure 2).

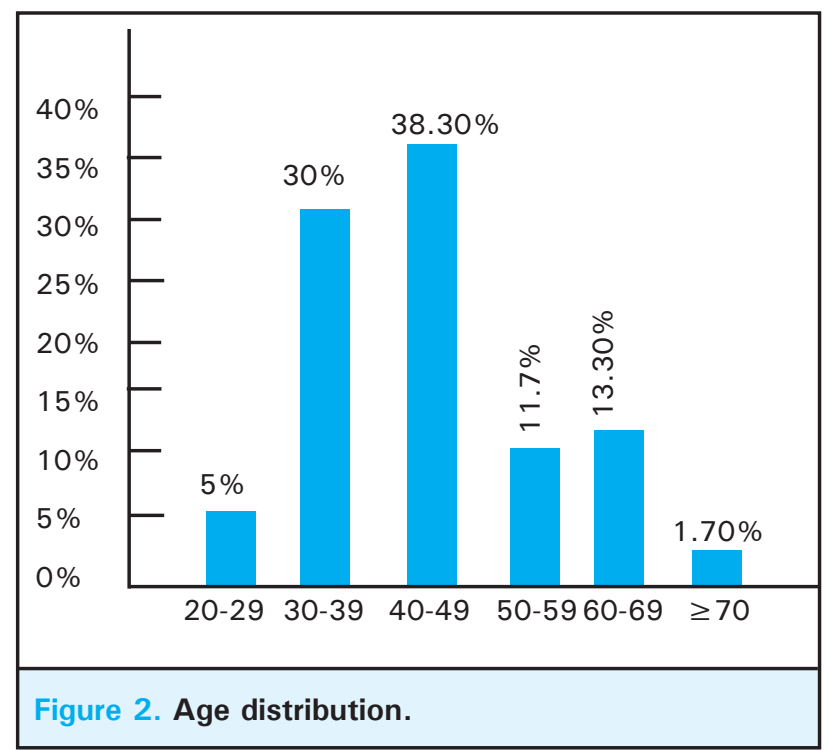

\section{DISCUSSION}

The common Upper Gastro Intestinal endoscopic findings as esophageal varices in our study was supported by a study done by Moazzam et al study, ${ }^{6}$ where they also found esophageal varices as the most common upper Gastrolntestinal endoscopic findings in 
portal hypertension (44\%). In our study non variceal Upper Gastrolntestinal findings as gastopathy, gastric and duodenal hyperemia, erosive gastritis were also one of the manifestations of chronic liver disease and is the commonest cause of upper GI bleeding. The causes of portal hypertension may be extra hepatic, intra hepatic, and post hepatic. Ruptured gastro esophageal varices are the commonest cause of bleeding. ${ }^{7}$ Other non variceal causes of bleeding include peptic ulcer disease, gastrodudenitis, Mallory weiss tear, hemostatic defects. ${ }^{8}$ Recently, portal hypertensive vasculopathy involving gastropathy, duodenal hyperemia has been recognized as an additional non variceal cause of $\mathrm{Gl}$ bleeding in portal hypertension. ${ }^{9}$

Portal hypertension in the developed countries who bleed are $40 \%$ due to non variceal causes where alcoholic cirrhosis and alcoholism predominate the aetiology of portal hypertension. As aetiological factors, demographic profiles differs in Nepal, above incidence of bleeding appears unlikely to be the cause of $\mathrm{GI}$ bleeding in developing countries. However occasional case reports are available on peptic ulcer disease as the cause of bleeding in portal hypertension in India. ${ }^{10}$

In the present study, most common cause of portal hypertension was cirrhosis accounting 47 out of 60 (78.3\%) followed by non-cirrhotic portal fibrosis eight out of $60(13.3 \%)$ and Extra hepatic obstruction five out of $60(8.3 \%)$. Among non cirrhotic causes noncirrhotic portal fibrosis was frequent eight $(61.6 \%)$ than extra hepatic obstruction five (38.4\%). This is in conformity with earlier reports from India, ${ }^{28}$ but slightly different in respect of common etiology for portal hypertension. This difference in etiology of portal hypertension reported from India may be due to special interest and research projects carried out by various centers on specific diseases or research projects going on in that department.

Among 60 portal hypertensive patients the most frequent upper $\mathrm{Gl}$ endoscopic change was found to be esophageal varices 59 (98.3\%) followed by gastropathy $49(81.6 \%)$, Gastric hyperemia 19 (31.6\%), duodenal hyperemia and erosive gastritis $16(26.6 \%$ each) and gastric varices 12 (20\%). However, duodenal ulcer $(6.7 \%)$, gastric ulcer $(5 \%)$ and found significant in number (gastropathy 49 (81.6\%), Gastric hyperemia 19 $(31.6 \%)$, duodenal hyperemia and erosive gastritis 16 $(26.6 \%$ each)), whereas in other study these findings were less frequent [(gastric ulcer $(4 \%)$, duodenal ulcer $(2.4 \%)$, fundal varices, gastritis $(4.2 \%)$ and portal hypertensive gastropathy $(1.2 \%)]$. The higher incidence of non variceal Upper Gl findings in portal hypertensive patients in present study in comparison with the earlier study is probably because of frequent use of NSAIDS and food habits.
In a study done by Mc Cormack et al, ${ }^{15}$ the esophageal varices was the most frequent upper GI endoscopic findings $81 \%$ followed by gastropathy $28 \%$, gastric varices 16 , duodenal ulcer $14 \%$, esophagitis $9 \%$ and gastric ulcer $7 \%$. This study support the findings observed in our study as esophageal varices is the most common upper Gl endoscopic findings followed by gastropathy. But the gastric varices was not found as a cause of upper GI bleeding in patients in our study. In another study, congestive gastropathy was the second most common abnormality (28\%) after esophageal varices $(81 \%)$ then gastric varices $16 \%$, esophagitis $9 \%$, gastric ulcer $7 \%$ and duodenal ulcer $14 \% .{ }^{13}$ The prevalence of endoscopic features in one study, they observed red signs in $40 \%$ of the patients with esophageal varices $\mathrm{Vs} 76 \%,{ }^{13}$ a mosaic pattern in $82 \%$ (Vs $94 \%$ in the Papazain et al), ${ }^{14}$ congestive gastropathy in $98 \%$ Vs $53 \%$ of Mc Cormack et al ${ }^{45}$ and gastric varices in $12 \%$ Vs $16 \%$ in the Palmer's study. ${ }^{16}$

In our study prevalence of esophageal varices were equally prevalent among cirrhotic and non-cirrhotic portal hypertensive patients, 46 out of 47 (97.9\%) and 13 out of $13(100 \%)$ respectively. Among non-cirrhotic patients, esophageal varices were present equally in EPO and NCPF (100\% in each). Gastropathy was more prevalent in cirrhotic patients with $87.2 \%$ (41 out of 47 ) vs. $75 \%$ (six out of eight) in NCPF followed by $40 \%$ (two out of five) in EPO. Gastric varices, chronic gastritis, gastroduodenitis and gastric ulcers were found only in cirrhotic portal hypertensive patients. However, duodenal ulcers were seen only in EPO $12.5 \%$ (one out of eight). Erosive gastritis was more prevalent in EPO, six out of eight $(75 \%)$ followed by three out of five $(60 \%)$ in NCPF, however, it was less frequent in cirrhotic portal hypertension seven out of 47 (14.8\%). In other studies, ${ }^{17-20}$ the prevalence of esophageal varices ranged widely between $60-95 \%$ in cirrhotic patients. The prevalence of esophageal varices ranged between $24 \%$ and $69 \%$ in cirrhotics with a mean of $59 \%$. In another studies, ${ }^{21,22}$ esophageal varices was present in $68 \%$ patients of NCPF by barium swallow study and another reported esophageal varices in $96 \%$ cases of NCPF.

In present study among esophageal varices, Grade II varices were the most common findings accounting $43.5 \%$ followed by grade IV $(28.26 \%)$ and III $(21.74 \%)$ among cirrhotic portal hypertensive patients. In NCPF and EPO, grade II varices were also frequent accounting $37.5 \%$ and $60 \%$ respectively followed by III and IV both accounting equal in frequency $25 \%$ in NCPF and $20 \%$ in EPO. In a study done by Ehab et al, ${ }^{71}$ among fifty cirrhotic patients esophageal varices were found in 45 out of $50(90 \%)$. Among them endoscopic findings showed 14 patients with grade I $(28 \%), 13$ 
patients with grade II (26\%), 16 patients with grade III $(32 \%)$ and one patient with grade IV $(2 \%)$. This study supported the findings observed in present study where variceal grading in cirrhotic portal hypertensive patients as grade II and III were frequent findings.

The prevalence of gastric varices in patients with portal hypertension was difficult to establish correctly but it ranged from $16-60 \% .24,25$ Gastric varices may be present in association with esophageal varices or independently. Isolated gastric varices may be seen in the absence of esophageal varices which was rare with a reported incidence of $8-12 \% . .^{22,24}$ In our study, the incidence of gastric varices was $20 \%$ in cirrhotic portal hypertension but not found in patients of NCPF and EPO. Similar results were reported in some other studies where prevalence of gastric varices reported was $19 \%{ }^{22}, 31 \%,{ }^{26}$ and $16 \%,{ }^{16}$ Sarin et al. ${ }^{22}$ noted gastric varices in $53 \%$ in cirrhosis, $20.25 \%$ in NCPF and $20.6 \%$ in EPO and $6.16 \%$ in hepatic outflow obstruction. This difference may be due to the difference in the stage of severity of disease at the time of study and sample size.

In the present study, incidence of erosive gastritis was $26.6 \%$, chronic gastritis was $13.3 \%$, gastric ulcer was $6.7 \%$, gastodudenitis was $5 \%$ and duodenal ulcer was $1.7 \%$ in case of portal hypertension. In the cirrhotic patients, erosive gastritis was found in $14.8 \%$, chronic gastritis in 17\%, gastric ulcer in $8.5 \%$ and gastrodudenitis in $6.5 \%$. In EPO, erosive gastritis was found in $60 \%$ and in NCPF erosive gastritis was found in $75 \%$ and duodenal ulcer was found in $1.5 \%$. It is similar to the previous studies. ${ }^{20,27-30}$

The prevalence of portohypertensive gastropathy was $81.6 \%$ in present study. This finding was in concordance with the findings of previous studies where PHG ranged from 51-94\%.14,15,31,32 In contrast, very high incidence of PHG has been reported mainly from the west. The incidence of PHG was slightly higher in cirrhotics $(87.2 \%)$ than in NCPF $(75 \%)$ and EPO $(40 \%)$. Similar findings have been reported by other indian investigators. ${ }^{22}$ The difference in incidence of PHG in cirrhosis and non-cirrhotics may be because of involvement of humoral factors, ${ }^{33}$ and more severe forms of liver disease in cases of cirrhosis. ${ }^{9}$

Severity of liver disease was adjusted by child pugh's. More than $80 \%$ of NCPF and EPO were of grade A and among cirrhotics, one third of the patients were of Grade A (31.9\%), $40.4 \%$ were of Grade B and $27.7 \%$ of Grade C. No cases of grade C was found in EPO and NCPF. Our study showed that decompensated liver diseases were found mostly among cirrhotic patients with portal hypertension.

\section{CONCLUSIONS}

The major upper $\mathrm{Gl}$ changes in cases of portal hypertension were esophageal varices, gastropathy and peptic ulcer disease (gastric and duodenal hyperaemia, gastritis, ulcers and erosions). Esophageal varices were equally prevalent among cirrhotic and non-cirrhotic portal hypertensive patients. The frequent variceal grading were grade II/II in those patients. Gastropathy is more prevalent in cirrhotic patients followed by NCPF and EPO. Gastric varices, chronic gastritis, gastroduodenitis and gastric ulcers were found only in cirrhotic portal hypertensive patients.

\section{REFERENCES}

1. De Franchis R. Evolving consensus in portal hypertension. Report of the Baveno IV consensus workshop on methodology of diagnosis and therapy of portal hypertension. J Hepatol. 2005;43:167-76.

2. Bhasin DK, Malhi NJ. Variceal bleeding and portal hypertension: much to learn, much to explore. Endoscopy. 2002;34:119-28.

3. Tsai MH. Splanchnic and systemic vasodilatation: the patient. J Clin Gastroenterol. 2007:41(Suppl 3): S266-71.

4. Bosch J, Abraldes J, Groszmann R. Current management of portal hypertension. Journal of hepatology. 2003;38:554-68.

5. Sonnenberg A. Factors which influence the incidence and course of peptic ulcer. Scand J gaastroenterol. 1988;155:19.

6. Saverbruch T, Kleber G. Upper gastrointestinal endoscopy in patients with portal hypertension. Endoscopy. 1992; 1/2: 45-51.
7. D'Amico G, Morabito A, Pagliaro L, Marubini E. Survival and prognostic indicators in compensated and decompensated cirrhosis. Dig Dis Sci. 1986;31:468-75.

8. Cales P, Zabotta B, Maskens C, et al. Gastroesophageal endoscopic features in cirrhosis. Gastroenterology. 1990;98:156-62.

9. DA. The American college of gastroenterology, bleeding registry: Preliminary findings. Am J Gastroenterol. 1997;92:924-28.

10. Forman LM, Lucey MR. Predicting the prognosis of chronic liver disease: an evolution from Child to MELD. Hepatolog. 2001;33:473-5.

11. Kamath PS, Wiesner RH, Malinchoc M, et al. A model to predict survival in patients with end stage liver disease. Hepatology. 2001;33(2):464-70.

12. Mc Cormack TT, Sims J, Eyre-Brook I, et al. Gastric lesions 
in portal hypertension: inflammatory gastritis or congestive gastropathy? Gut. 1985;26:1226-32.

13. Rosemurgy A, Zervos E. Management of variceal hemorrhage. Curr Probl Surg. 2003;40(6):253-344.

14. A Papazian, A Braillon, J L Dupas, et al. Portal hypertensive gastric mucosa: an endoscopic study. Gut. 1986;27:1199-203.

15. Mc Cormack TT, Sims J, Eyre-Brook I, et al. Gastric lesions in portal hypertension: inflammatory gastritis or congestive gastropathy? Gut. 1985;26:1226-32.

16. Palmer KR, Penman ID. Diseases of the alimentary tract and pancreas. In: Haslett C, Chilvers ER, Hunter JAA. Davidson's principles and practice of medicine. 18th ed. Edinburgh: Churchill livingstone; 1999. p. 599-681.

17. Cales P, Zabotta B, Maskens C, et al. Gastroesophageal endoscopic features in cirrhosis. Gastroenterology. 1990;98:156-62.

18. Christensen E, Fauerholdt L, Schlichting P, Juhl E, Poulsen H, Tygstrup N. Aspects of the natural history of gastrointestinal bleeding in cirrhosis and the effect of prednisone. Gastroenterology. 1981;81(5):944-52.

19. Farooqi JL, Farooqi, RJ. Endoscopic management of bleeding peptic ulcer. J coll AA physicians surg Pakistan. 2001;11:530-4.

20. Buccino RU, Boglialo G, Ferrara M, Pietropaolo V, Miscusi $\mathrm{G}$, et al. Endoscopic approach to patients with portal hypertension: a complex diagnosis. A retrospective study based on 10 years experience. Surg Ensodc. 1990;4:76-9.

21. Tondon BN, Nundy S. Portal Hypertension in India, New Delhi. Rajgarhia Clinical Liver Research Unit. 1983.
22. Sarin S.K et al. Factors influencing development of portal hypertensive gastropathy in patients with portal hypertension. Gastroenterology. 1992;102:994-9.

23. Siciliano M. Rossi L. Congestive gastropathy in liver cirrhosis. Minerva med. 1993; 84:403-8.

24. Groszmann R, Bosch J, Grace N. Hemodynamic events in a prospective randomized trial of propranolol versus placebo in the prevention of a first variceal hemorrhage. Gastroentrology. 1999;99:1401-7.

25. Jensen DM. Endoscopic screening for varices in cirrhosis: findings, implications, and outcomes. Gastroentrology. 2002;122:1620-30.

26. Dib N, Oberti F, Cales P. Current management of the complications of portal hypertension: variceal bleeding and ascites. CMAJ. 2006;174(10):1433-44.

27. Singh DS, Prabhatvardini S, Chandra D, Srivatava KK, Chandra Shekhar S. A study of gastric secretion and peptic ulcer in Hepatic cirrhosis. J Ind Med Assoc. 1980;75:193-6.

28. Child C, Turcotte J. The liver and portal hypertension. In: Child CI, editor. Surgery and Portal Hypertension. Philadelphia, USA: WB Saunders;1964. p. 50-8.

29. Pugh R, Murray-lyon I, Dawson J. Transection of the esophagus for bleeding esophageal varices. Br J Surg. 1973;60:646-9.

30. Huma $\mathrm{Q}$, Waqaruddin A, Zuberi SJ. Triple therapy in duodenal ulcer healing A follow up study. J Pak Med Asssoc. 1996;46:1994.

31. Khuroo M, Steele R. A comparison of omeperazole and placebo for bleeding peptic ulcer. $\mathrm{N}$ Engl J Med. 1997;336:1054. 